\title{
Fire Safety of Historical Buildings: Principles and Methodological Approach
}

\author{
José L. Torero ${ }^{1}$
}

\begin{abstract}
This paper addresses an issue rarely contemplated in the management of historical buildings, fire safety. There is an implication that "compliant" means "safe" and that the goals and objectives of compliance are perfectly aligned with those of fire safety. In the case of historical buildings, this is a mistake that has resulted in the loss of major historical buildings through the centuries. This paper presents a framework of analysis that uses adequate tools to evaluate and establish true performance assessment. The objective is to adequately define and implement the goal of fire safety. This paper is not a traditional research paper in that it does not describe experiments, computations or analysis. Instead, this paper proposes, through an example of application, a critical overview of problems incurred when evaluating fire safety on the basis of solutions issued from prescriptive approaches. In the process, this paper highlights the value of a comprehensive performance-based approach. A performance-based analysis emphasizes an approach to design that values the inherent features of historic buildings. This could potentially result in minimum and rational alterations that meet the goals of fire safety while also achieving other restoration objectives.
\end{abstract}

Keywords: fire safety, fire protection, regulatory compliance, fire dynamics, life safety.

\section{Introduction}

The implementation of fire safety in the built environment has been traditionally a very prescriptive process. The goal is one of protecting life against the hazard of fire. While fire safety is directly related to the laws of physics and the management of human behavior in a high-risk situation, these laws of physics are rarely invoked and instead its implementation is generally associated to code compliance. Codes, incorporate elements of human behavior and fire dynamics, nevertheless they are the result of multiple compromises, many of which are associated to a temporal perception of safety, the available tools and the construction typologies. What was perceived as safe in the past might not be perceived as safe today. Buildings are thus constantly being retrofitted so as to be updated to new code requirements. These code requirements, in turn, are deemed to provide an acceptable level of safety as it is perceived today. The implication is that compliance means safe and that any building that is not code compliant, to the current prescriptive requirements, is therefore unsafe and needs to be retrofitted. Obviously, there is a limit to this approach. Many times, buildings cannot be retrofitted and therefore codes provide provisions for grandfathering non-compliant structures as well as for the use of performance based tools. Grandfathered buildings will never be perceived as safe and therefore many concessions on the building use become necessary. Performance based design is rarely used as such, and when it comes to historic

\footnotetext{
${ }^{1}$ Professor of Civil Engineering, Department of Civil Environmental and Geomatic Engineering, University College London, UK, j.torero@ucl.ac.uk
} 
buildings, its use is mostly directed towards obtaining certain specific equivalencies that allow to ascertain that omissions to the codes are acceptable.

When it comes to historic buildings, the building incorporates a contextual value that is generally not accounted by codes. Certain features of the building (ex. architecture, ornaments, construction techniques) cannot be modified without diminishing the value of the building. Furthermore, many times the building will house inherently valuable objects that are part or not of the fabric of the building (ex. murals, paintings, art object, religious objects, etc.). Many of these objects and their use can represent a hazard themselves (ex. preservation fluids in a natural history museum, fabrics in a textile museum, candles in a church, etc.). These features of historic buildings make them a challenge because it becomes unacceptable to alter the building to include modern fire protection features (ex. smoke detectors, sprinklers, fire rated stairs, etc.) and it is many times impossible to manage hazards in a manner consistent with code assumptions (ex. no combustibles in egress paths, fuel characteristics corresponding to the assumptions embedded in the design of fire protection systems, etc.). Thus, the fire safe design of a historic building represents a challenge. The challenge is based on the need to achieve an adequate level of safety, in a building that has many alteration constraints and where common tools for fire protection become unacceptable.

The conventional approach of attaining compliance or to implement equivalent solutions by means of bridging performance-based design has proven inadequate resulting in many losses where the final explanation is that the building was non-compliant and therefore the failure should be expected.

Detailed reviews of many aspects of fire safety in the context of historical buildings have been written [1] and the unique features of historical buildings that affect fire safety have been recognized by many and have been discussed many times in great detail. Nevertheless, these reviews focus on framework type explanations of the different problems but do not offer a means to take advantage of the inherent features of the historical buildings.

Carattin and Brannigan [2] provide one of the most eloquent reviews of the complexities associated to the implementation of fire safety in historical buildings. Not only they address the multiple variables of the problem, the major constraints associated by the nature and value of the buildings but they also study in detail the many limitations of the analytic tools commonly used for establishing if a building is fire safe. Carattin and Brannigan establish in their review [2] the weakness of codes and standard design practices when addressing historic structures. Their concern is summarized when they state that: "because they are called "buildings," designers and code writers and enforcers routinely assume that they are simply older versions of the modern buildings they work with. But they are not." The review covers several examples and relevant issues nevertheless is centered around life safety and only briefly discusses other issues associated to the fire safety strategy.

The focus of most of the work on fire safety of historical buildings remains on life safety and the means to quantify in a comparative manner the importance of the building and its contents is not clearly discussed. A very good example of this approach is the review by Bernardini [1] where, after a detailed explanation of the 
issues, the focus is placed back on effective means of wayfinding as a mechanism to aide egress without major modifications to the building fabric. Reviews that address recent advances in codes and legislation treat fire in a simple manner and remain focused in the adaptation of buildings to meet current standards while taking into account the desire to minimize intervention ("older versions of the modern buildings" [2]). None of these changes take advantage of the inherent safety of the historic buildings or propose novel approaches towards a quantitative analysis of safety [3].

Studies have addressed management as a means of improving life safety in historical buildings, but the principles evoked are a simple and direct extrapolation of approaches used for modern buildings [2] without a direct link to the inherent features specific to historic buildings [4].

The review by Marrion [5] attempts to describe performance criteria that could be used as a basis for design. In this review a lessons-learnt approach is presented, where a series of assumed causes for fires are presented but which are not based on thorough fire investigations. Thus, the link to adequate intervention is tenuous. Methods to deliver performance based designs have even been codified [6,7], nevertheless as described by Watts and Solomon [8], much of what is presented in NFPA 914 [6] relies on judgments that are partly subjective and on agreement of the involved parties, including the authority having jurisdiction. The focus therefore still reverts back fully to life safety and is tainted by expert judgement. Carattin and Brannigan [2] warn against expert judgement as a means to address fire safety in historic buildings.

One of the clearer attempts to use a performance approach towards the analysis of a historic building addresses the refurbishment of the "Teatro Comunale Niccolò Piccinni" in Bari [9]. Here, a combination of fire protection measures and calculation tools are used to deliver what is deemed as an acceptable solution. This solution incorporates structural components, new compartmentalization requirements, active fire protection measures and major modifications of the architecture (stairs). Despite the detailed explanations provided on the measures taken, there is no quantitative assessment on how the objectives of the refurbishment were attained or on how the inherent features of the building supported the proposed solution. The exception is the structural analysis where performance criteria are defined but they are established either in regulatory terms (i.e. Fire Resistance [10]) or by means of arbitrary thresholds (i.e. $400^{\circ} \mathrm{C}$ fires). These criteria are valuable in that they serve to assess the robustness of the structure but do not take account the actual fires possible within the building. In some manner, the treatment of the historic building remains as that of an older version of a modern building [2].

Approaches that deviate from life safety have also been published. Many of these studies have produced frameworks that analyze in a systematic manner risk within historic buildings or the potential upgrade options that can be used to upgrade the fire safety of historic buildings. These studies use complex tools such as Analytic Hierarchy Process [11] where all options are tested against constraints such as cost or valuable historical attributes. Many of these studies rely on expert opinion but do not define what constitutes an expert (against the warnings of reference [2]) or how the risk assessment can be transformed into design approaches that take 
advantage of the inherent features of the building [12]. In some cases, these risk assessment tools have even been incorporated into Geographic Information Systems (GIS) [13] without resolving the basic principles of fire safety and many times defining fire safety on the basis of incorrect principles such as ignition risk. In a similar manner, studies have suggested the use of BIM for the purposes of addressing fire safety, in particular the Historical Building Information Modelling (H-BIM) approach. While accurate digital representations of historic buildings will be with no doubt valuable to achieve an optimized approach to fire safety, none of these approaches has yet incorporated any of the fundamental issues of fire safety [14]. These studies fail in several manners, first they do not establish in a quantifiable manner the safety objectives, second, they do not take into account the beneficial attributes of the building and finally they do not address in a quantifiable manner the impact of proposed modifications. In the absence of these three fundamental features these approaches cannot be used.

What would be discussed here is an alternative approach that puts forwards the fact that life safety and fire dynamics are processes that evolve in space and time and that are governed by the laws of physics and by well characterized human behavior. A such, if the objectives are clearly established and the tools are mastered by competent professionals, a safe but non-compliant historic building can be obtained with minimum intrusion to the historic value and significance of the building and without limiting its use or contents.

\section{Current Approach to the Fire Safety Strategy}

\subsection{Fire Risk Analysis}

Currently, a prescriptive fire safety strategy is based on the following premises. A building is expected to have a fire in its life. Fires, if considered in the most general way, are much higher event probabilities for a building than any other hazard. Therefore, the probability of a fire is effectively one. This is very important because it changes the concept of risk. Normally, risk is defined by equation (1) [15]

$$
R_{g}=P_{g} x C_{g}=P_{f} x C_{f} \approx C_{f}
$$

where $R_{g}$ is defined as the general risk, $P_{g}$ is the probability of the event and $C_{g}$ the consequences. The subindex "f" corresponds to a fire where $P_{f} \approx 1$ and therefore risk in the event of a fire is purely the management of consequences.

The assumption that a fire will occur equates to the acceptance that an ignition event will happen. This does not imply that this event will have significant consequences, but simply that it will happen. What is termed here as a fire event includes all possible scenarios and thus is an event that precedes the progression of the fire. For an ignition event to become a fire scenario, there have to be interactions between the fire, the building fabric, the fire safety measures and potentially the occupants. Form this initial fire event, scenarios will develop and there will be some that are more probable than others. Nevertheless, for the purpose of this paper, the evolution towards a scenario will be incorporated in the analysis of consequences. 
This approach to event probabilities is not common when analyzing other hazards like earthquakes or floods. In these fields, the consequences need to be managed but they are generally subordinated to the evaluation of the event probability [1]. For other hazards, we design for events of a certain acceptable probability and therefore we can define loads against which we can evaluate the design (ex. one in one-hundred-year event). Therefore, performance assessment becomes a natural path. In the case of fire, the objective is simply to manage the consequences of an event that will happen. In the absence of a fire safety strategy many fires will result in unacceptable consequences, so the purpose of the fire safety strategy is to manage the consequences in a manner such that the probability of a fire resulting in unacceptable consequences is sufficiently low. The manner by which codes establish what is a probability that is low enough that it can become acceptable to society is integrally based on life safety [16-18]. In the case of historical buildings, given the value society assigns to the building and its contents, this approach is insufficient.

The focus on life safety has limited the capacity to develop fire safety strategies that carefully incorporate the characteristics and value of the building and its contents. This is a fundamental weakness when it comes to respectful restoration but also limits the rigor applied to the development of strategies that pertain the approaches used towards safe management of restoration sites.

\subsection{Current Prescriptive Approach}

Prescriptive approaches will manage fire events by first defining the characteristics of the event. First, the event will be considered a single accidental fire that will be placed and defined according to scenarios that are considered possible. For example, if a building includes a kitchen, a kitchen fire becomes part of the consideration. Multiple events are excluded by separating them as criminal events (i.e. arson). A designer is therefore not required to design for multiple events. Many historical monuments have been destroyed in acts of war by circumventing this assumption [19] which demonstrates that proactive introduction of multiple events fully dismantles the fire safety strategy [20].

Buildings are classified as a function of their occupancy. Occupancy not only defines the use of the building but also defines the type and quantity of combustibles that will be expected to be present. Statistics have been developed for traditional occupancies (ex. assemblies, residential, hotels, hospitals, etc.) determining typical fuels and typical quantities. Thus, by providing a classification the potential fires against which the countermeasures will be defined are fixed. Codes will define then the fire growth as a function of tabulated fires. The most common approach is presented in equation (2) [21]:

$$
\dot{Q}=\left[\pi \Delta H_{c} \dot{m}_{f} V_{s}\right] t^{2}=\alpha t^{2}[k W]
$$

where $\dot{Q}$ is the heat release rate and is the primary quantity that characterizes the fire size, $\Delta H_{c}$ (heat of combustion), $\dot{m}_{f}$ (burning rate) and $V_{s}$ (flame spread rates) are material properties that define the propensity of a combustible to release energy. " $t$ " corresponds to the time from ignition and represents the rate of growth. All material properties are then integrated into a global parameter, $\alpha$, which is then classified. Most codes will 
classify materials as sustaining a slow growing fire $\left(0.0029 \leq \alpha<0.0117\left[\mathrm{~kW} / \mathrm{s}^{2}\right]\right)$, medium growing fire $\left(0.0117 \leq \alpha<0.0469\left[\mathrm{~kW} / \mathrm{s}^{2}\right]\right)$, fast growing fire $\left(0.0469 \leq \alpha<0.1876\left[\mathrm{~kW} / \mathrm{s}^{2}\right]\right)$ and ultra-fast growing fire $\left(0.1876 \leq \alpha\left[k W / s^{2}\right]\right)[21]$.

The classification of the fire event (as a pre-defined evolution of the heat release rate in time) allows to establish the event that is to be used as input when analyzing the impact of a fire on a building and its occupants. As explained before, the primary objective of a fire safety strategy is life safety. Thus, a primary objective of a fire safety strategy is to allow people to evacuate safely. Given the occupancy, the characteristics and quantity of people will be defined and thus typical egress times can be established. To guarantee appropriate notification of the occurrence of a fire, so that the onset of egress can be well controlled, building regulations will require appropriate detection and alarm systems. These systems are consistent with the occupancy, so while in residential buildings point detectors will alarm the residents and only the residents, in hospitals, smoke detectors will be connected to alarm systems and to building managers for a coordinated egress approach. Many variables will affect egress, these include behavioral variables as well as building characteristics [1,2]. These egress times are called the Required Safe Egress Time (RSET) [22]. The building will then be designed in a manner such that a fire that follows a certain growth classification will not attain untenable conditions anywhere in the building before all occupants have evacuated. Tenability is difficult to define but in general terms means conditions that challenge the safety and wellbeing of occupants or that are perceived as challenging by occupants. As such, carbon monoxide concentrations can be used as a tenability criteria because it can incapacitate occupants but also visibility because occupants will feel challenged by waking into a smoke laden space. Many guidelines will provide quantitative criteria on tenability mostly based on carbon monoxide concentrations, temperatures and visibility [21].

The Available Safe Egress Time (ASET) is the time required for any specific environment in a building to attain untenable conditions. In a building deemed to be safe ASET will always be much greater than RSET [22]. When the fire grows too fast and the occupants do not have sufficient time to evacuate then other provisions have to be put in place. If spaces are too large and therefore travelling distances are too long, then compartmentalization can be introduced either to protect egress paths or to stop smoke from entering adjoining spaces. The fire growth rate can also be controlled to increase the ASET. Sprinklers can be used to reduce the fire growth rate while requirements for fuel control can also be introduced. Both will effectively reduce or limit the value of " $\alpha$ " (Equation (2)). Compartmentalization is generally referred to as passive fire protection while sprinklers as active fire protection. Engineering tools can be used to determine different combinations of active and passive measures that deliver an adequate level of safety.

Compartmentalization includes all components of the barriers including doors and service penetrations. To guarantee compartmentalization strict rules of testing are implemented to provide certification to all building components. Certification is attained by means of fire resistance testing [10] which is a furnace test that is intended to reproduce a worst-case scenario and provide a time to failure for all components (i.e. a time to attain a critical failure temperature). 
To facilitate egress all paths (ex. corridors, stairs, doors, etc.) for evacuation have to be designed ergonomically so that people can flow freely. The direction of egress shall also be signaled appropriately.

Redundancies have to be introduced, so compartmentalization is supported by active control of pressure in areas that need to be free of smoke so that air flows from the safe place towards the fire and not the opposite (ex. Pressurized stairs). Means of egress can be duplicated in case one is blocked by smoke or fire. The fire service is the ultimate redundancy to the overall strategy. Details on the components and implementation of a fire safety strategy can be found in reference [22].

Redundancies and factors of safety are introduced not only to provide robustness to the design but also to compensate for variability and uncertainties. The development of a fire as well as the behavior of people carry significant uncertainties. Any analysis needs to consider these uncertainties. In the case of prescriptive design, the treatment of variability and uncertain is implicitly incorporated in the code provisions, while in the case of performance based design appropriate treatment of uncertainties is part of professional practice. Given that this paper focuses on establishing a methodological approach, there will be no further discussion on variability and uncertainties, nevertheless, their appropriate treatment is clearly part of the methodological approach.

Through the entire egress process the structure needs to maintain stability, so all load bearing structural components will be thermally protected so that their temperature does not reach critical values were significant reduction of structural strength occurs. The required thermal performance is defined once again as a fire resistance by means of large scale testing [10]. Under these circumstances, codes will establish that there is no need to check for stability of the structure under the effects of a fire [23]. A fire that can challenge stability and is capable of leading to progressive collapse is therefore considered as an extraordinary (i.e. low-probability) event. Buildings have included an explicit structural performance analysis for fire only in the last 20 years and even then, only unusual, highly important or unique buildings have justified this engineering effort [24].

\subsection{Outcome of a Fire Safety Strategy}

A key weakness of the fire safety prescriptive approach is the fact that the overall outcome is never assessed. Codes will deliver solutions that are fitting to the classification, nevertheless, these solutions are not solutions to the fire safety strategy but to the components of the strategy. As an example, the National Fire Protection Association (NFPA) in the USA [25] has two opening codes NFPA1 and NFPA101, NFPA1 states the life safety goals of the code and NFPA 101 the different classifications and the basic principles of the solutions proposed. Other documents within the code will describe in more detail some special classifications (ex. hospitals, industrial facilities, etc.) but in general most other documents within the code will prescribe detailed solutions to the different protection components. As such, documents like NFPA 13 will describe sprinkler systems, NFPA 72 Detection and Alarm systems, etc. Compliance with the code is therefore defined as incorporating the correct components and implementing them adequately. There are no explicit objectives of overall fire safety defined by the codes. Given this approach, it is extremely complex to establish an "equivalent level of safety." For historic buildings this is paramount because code compliance then is only possible if all the protection 
measures prescribe by the code for the occupancy are implemented and implemented according to the requirements of the code.

\section{Historic Buildings}

Historic buildings differentiate themselves from other buildings in that the building in itself has sufficient value that it not only needs to be preserved in as intact a manner as possible but also needs to be explicitly protected. In contrast to conventional code compliant buildings, where life safety is the primary and single goal of compliance, in historic building other objectives gain significant importance. Life safety will remain a primary goal but it is no longer the single primary goal of fire safety. Historic buildings are part of national patrimony, many times hold objects of unquantifiable value and in most cases buildings and contents are irreplaceable. This added constraint requires changes to the approach towards fire safety. This change has to improve the strategy to account for the protection of the building and objects of material and historic value [1-9].

\subsection{Fire Growth and Fire Damage}

Fire growth no longer can be assumed simply as a function of material properties and a growth rate that is allowed to increase as a function of time. In a conventional building fire growth will, when unattended, lead to flashover. Flashover corresponds to the moment when the smoke layer produced by the fire reaches a sufficient temperature and soot volume fraction that results in enough radiation so that all other combustible objects ignite. At this point the compartment gets filled with hot smoke. The fire in this case will result in major damage to that compartment and all its objects [26]. Figure 1(a) shows a typical photograph of the aftermath of a post flashover fire. As it can be seen, all objects within the compartment have been destroyed and it is very likely that significant structural damage would have occurred. If this would have been a historical building, it is very likely that this type of fire would have resulted in unacceptable damage, even if life safety was not compromised. In a conventional building this might not be a major issue but in a historic building this could potentially represent a major loss. Thus, for historic, buildings a fire generally cannot be allowed to grow. There are two means by which fire growth can be controlled, by means of compartmentalization and by means of active fire suppression. Compartmentalization is many times impossible in a historic building because the structure cannot be modified, thus the importance of fire suppression increases. There is generally reluctance to introduce fire suppression systems in historic buildings for two primary reasons. The first is that it represents an intrusion to the architecture, and this is many times unacceptable. Second, in case of an accidental sprinkler activation, water damage can be as devastating as a fire [2]. The second issue is truly not a significant one. While conventional suppression systems might experience these problems, tailor made systems should not. A dry pipe with higher level of reliability and multiple activation devices is always a possibility [25]. The first issue is more relevant and needs to be carefully considered. Concealed sprinklers are possible but still represent an intrusion to the architecture and many times it is impossible to introduce the piping without damaging valuable features of the building. 


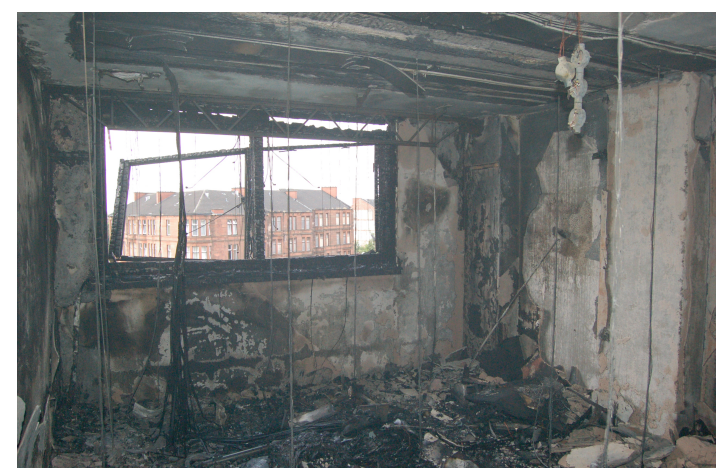

(a)

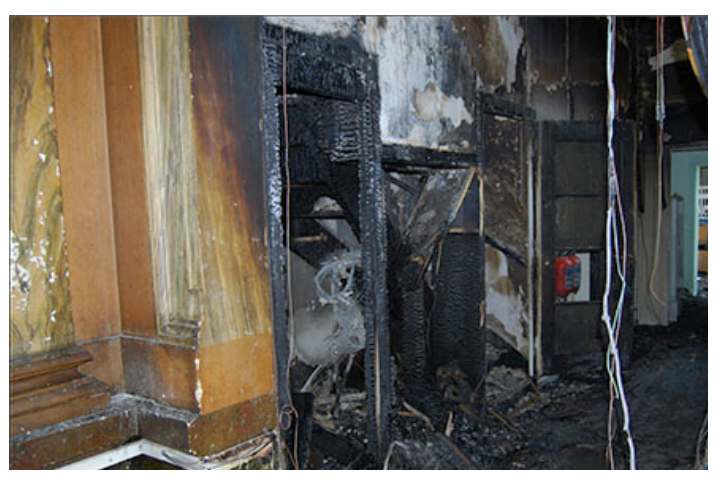

(b)

Figure 1. Consequences of a fire (a) a post flashover fire with generalized damage [27] (b) a fire that not reached flashover with localized damage (University of Geneva) [28]

\subsection{Controlling Fire Growth}

As an example, Figure 1(b) presents an image of the University of Geneva building after a significant fire [28]. In some areas of the building the fire reached flashover damaging objects but also the fabric of the building. Sectors of the roof were severely damaged and require complete replacement. Instead, other areas, like those illustrated on Figure 1(b) only showed localized damage. Thus, the loss was not complete and many valuable elements of the architecture could be cleaned and reconditioned during the 2014 rehabilitation of the building [28]. This example serves to illustrate that given certain characteristics of a building, conditions might be such that flashover will not occur. While this example will be discussed in much more detail later, it is useful to show that these characteristics can be exploited to protect the building.

The main reason why flashover did not occur is because of the large volume of the public areas. Flashover requires for the smoke to reach a certain temperature (generally assumed to be around $600^{\circ} \mathrm{C}[6,7]$ ) and contain a certain concentration of soot. The soot volume fraction defines the emissivity of the smoke and the temperature its radiative power [21]. Radiation from the smoke layer delivers heat to all combustible materials and once a critical value for ignition is attained, all combustible materials will ignite and flashover will occur [26]. The temperature and species concentrations of the smoke layer are defined by the smoke migrating upwards from the fire and into the smoke layer. The temperature of the smoke and species concentrations are correlated through energy and mass conservation equations [21]. Equation (3) shows an example of the energy conservation equation for the smoke

$$
T_{S}=T_{\infty}+\frac{\dot{Q}_{c}}{\dot{m}_{A} C_{p}}
$$

Where $T_{S}$ is the temperature of the smoke, $T_{\infty}$ the ambient temperature, $\dot{Q}_{c}$ is the fraction of the energy released by the fire delivered to the smoke, $\dot{m}_{A}$ is the mass of air entrained by the fire and $C_{p}$ the specific heat capacity of the smoke. A similar conservation equation can be constructed for the soot volume fraction showing 
that it will also depend on the heat released by the fire $\left(\dot{Q}_{c}\right)$ and the mass of air entrained $\left(\dot{m}_{A}\right)$. The mass of air entrained can be obtained by a simple correlation of the form [29]

$$
\dot{m}_{A}=C \dot{Q}_{C}{ }^{1 / 3} H^{5 / 3}
$$

Where $C$ is called the entrainment constant and is an empirical value corresponding to a specific type of fire and $H$ is the smoke free height between the floor and the smoke layer. This height will initially be the floor to ceiling height of the room but later as the smoke accumulates it will decrease. Combining Equations (3) and (4) it can be established that the temperature (and similarly concentrations) will increase as the fire increases in size and will decrease as the floor to ceiling height increases. Conventionally, sprinklers will be used to reduce the fire size and thus prevent flashover but also the building design can be used to increase the floor to ceiling height and also prevent or delay flashover. While this analysis is simplistic in nature it shows that a feature of an existing building, such as the floor to ceiling height, can be used to compensate for the omission of a sprinkler system.

\subsection{Compartmentalization and Life Safety}

Compartmentalization is also a very important issue when it comes to historic buildings. General building code requirements worldwide will indicate the need to use protected means of egress (ex. [25]). This generally means that emergency stairs need to be provided and that these have to be introduced with a predefined separation that does not excide prescriptive maximum egress distances. Emergency egress paths have to be enclosed by fire resistant construction. The layout of most historic buildings was defined most times prior to the introduction of maximum egress distances in the codes (in most countries these requirements appear no earlier than 1920 's $[19,20])$. Therefore, most historic buildings do not have provisions of enclosed stairs. Adding or enclosing stairs generally requires extraordinary interventions. When addressing a historic building, it is therefore necessary to establish if these enclosed stairs are necessary and what alternative means and provisions can be used to compensate for the absence of such enclosures. In a similar manner, corridors many times exceed maximum egress distances, thus codes will require barriers to break the corridor to guarantee safe egress. Again, these barriers represent major intrusions and therefore need to be addressed with some care. The management of smoke to allow for extended travel distances and unenclosed stairs in a historic build will be used as an example of the type of analysis required.

It is important to clarify, that smoke management is used here only as an example of an alternative form of intervention. There will be situations or potential occupants groups that will not benefit from this specific approach. A detailed performance analysis should take into account all those considerations.

\subsection{Fire Resistant Doors}

A critically important feature of compartmentalization are the doors. Performance assessment of fire doors requires testing of a door system that includes the door, the frame, the hinges and all other fixtures. The system 
needs to protect the safe are from ingress of fire and smoke. In historic buildings, doors are many times, inherent fixtures of the architecture and therefore it is desirable not to intervene to attain a required level of fire resistance. Figure 2 shows a good example of such doors. The doors come from the same building at the University of Geneva and during the refurbishment it was highly desirable not to alter the doors and fixtures. Maintaining these doors requires a detailed analysis of their capacity to withstand the penetration of smoke and flames. In general, it is easy to demonstrate that massive timber doors are capable of sustaining the heat fluxes of a generalized fire for an adequate period. It is much more difficult to address their capacity to contain smoke. It is very common that minor modifications, that introduce adequate seals and manage the relative motion between frame and door, will be required and therefore detailed dialogue with other stakeholders (i.e. architects and heritage experts) will be necessary.
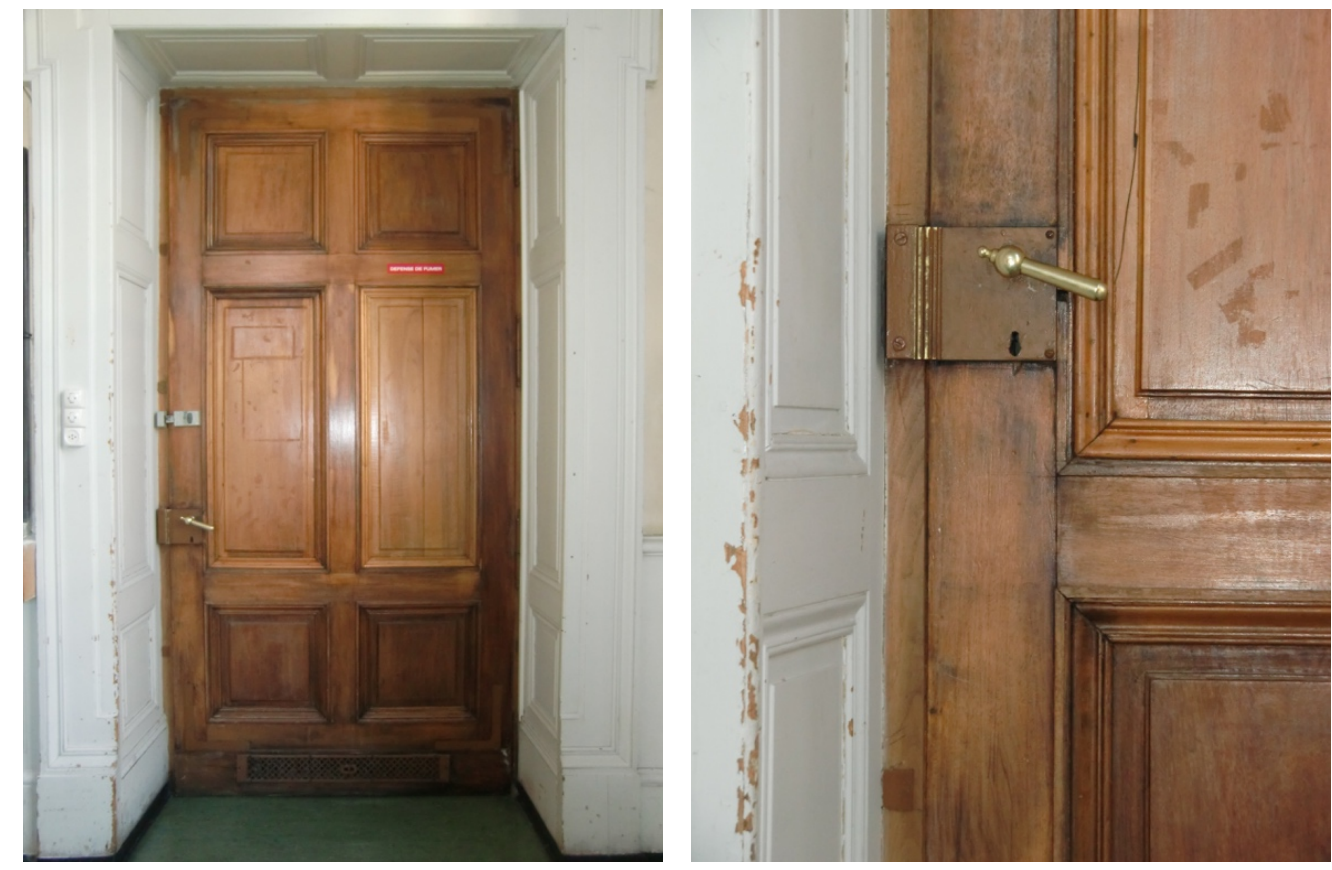

Figure 2. Historic doors and detail of fixtures used at the Bastions Building, University of Geneva

\subsection{Fire Resistance and Structural Integrity}

When following a prescriptive approach, structural integrity and compartmentalization is guaranteed by means of fire resistance testing. Structural elements and compartmentalization components need to be tested in a destructive manner to establish their fire resistance. This will generally be impossible for historic buildings. Structural solutions of historic buildings tend to be very different from current constructive methods. Therefore, these solutions have never been tested for compliance and therefore do not represent rated construction. Code compliant constructive solutions are generally included within official listings [30] that describe performance as obtained through testing. Figure 3 shows examples of structural systems with protection dating to the $19^{\text {th }}$ century. A system of the nature of Figure 3(b) will most likely achieve the required fire resistance, nevertheless 
it will not be certified (and therefore non-compliant) and will require cover if the building was to be rehabilitated. As structural system like Figure 3(a) is very similar to that of 3(b) but it has no fire protection. This system will also be deemed non-compliant. Both cases are different but will both be treated in a similar manner by codes. Detailed Finite Element Models (FEM) can establish the structural behavior of these systems. To establish if the structural behavior meets the needs, a temperature distribution for the structural system is needed [31]. The temperature distribution of the gas phase and associated heat transfer coefficients can be obtained using Computational Fluid Dynamics (CFD) models but in most cases (due to the simple geometries and very different time scales for the heating of solids and gases) much simpler models can also be used [26]. A simple zone model will be illustrated in the next section [21]. A subsequent heat transfer analysis will then deliver the temperature evolution of the structural elements. The FEM models can serve to provide a time equivalency for the structure that defines what could be the potential fire rating for a historical structure. As indicated above, this is a significant departure from prescriptive methods where performance assessment of the structure is not required.

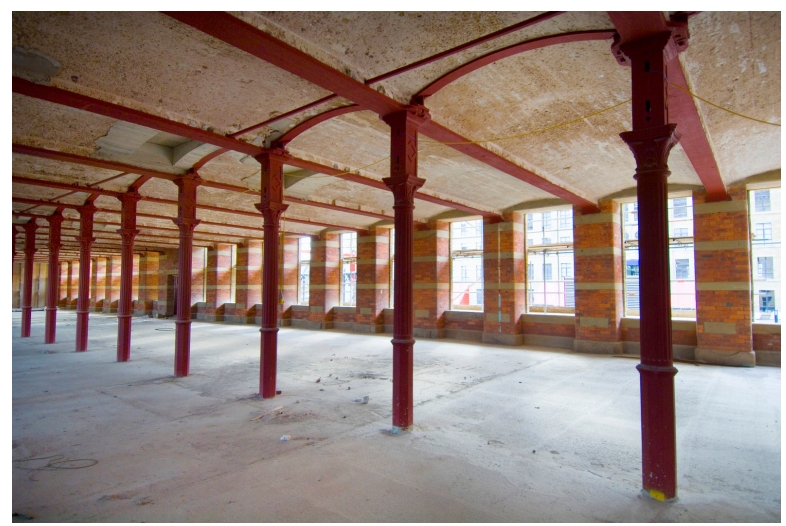

(a)

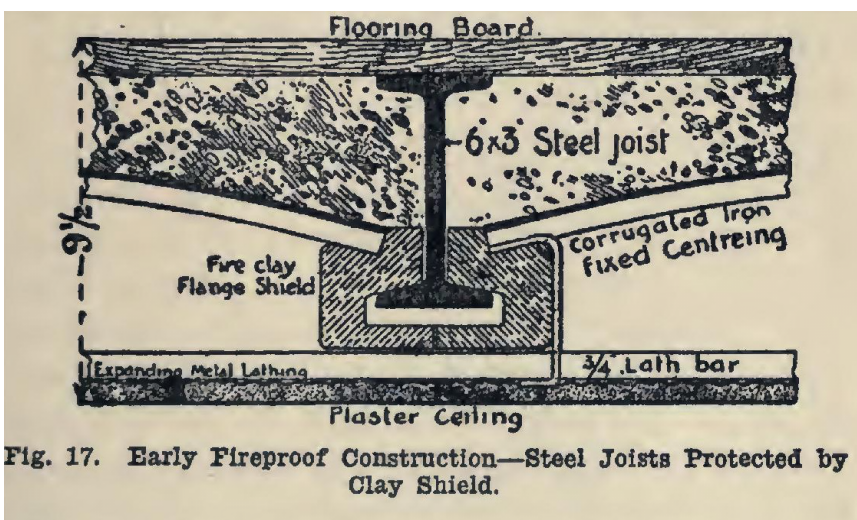

(b)

Figure 3. Historic structural slab (a) photograph of a historic vaulted ceiling (b) Section of a $19^{\text {th }}$ century protected beam

An important aspect of structural assessment is the determination of the thermal solicitation potentially imposed by a fire. Structural analysis traditionally uses a concept of a load being applied to the structure. This load will follow a probabilistic distribution that will be defined within a code or a guideline. In the case of fire, this is not the case. The nature of the fire is affected by the building and the fuel available. As indicated by Equations (3) and (4) temperatures depend on geometrical features such a floor to ceiling heights. Furthermore, the nature of the constructive materials (ex. Wood) might make the construction part of the available fuel. All these aspects need to be carefully considered. Once the temperature evolution within the building is established and heat transfer to the structural systems is calculated, then the structure will evolve as the temperature increases. The evolution can result in the deterioration of mechanical properties (ex. As indicated in Eurocode 5 [31]) but also thermal expansion and thermal bowing can result in the generation or relaxation of mechanical loads. This opens the possibility to the introduction of structural interventions, of minor impact to the historic value of the building, that could nevertheless reduce the loads generated during a fire. While the potential for this type of intervention exists and could be immensely valuable to the preservation of a historic building, to the knowledge of 
the author, this approach has never been implemented. Instead the conventional approach is to ignore all the potential benefits of the existing structural design and to either replace it by a rated alternative or to add encapsulation to a level where the thickness of the encapsulation is in itself sufficient to comply with the prescriptive requirements. In the domain of structural integrity, current prescriptive practices in the structural and fire safety engineering community have not evolved in a manner that enables the use of modern analytical tools to determine the true capacity of a historical structure to withstand a fire.

\section{Example - Smoke Management for The Bastions Building University of Geneva}

Overall, the basic principle of analysis of fire safety for historic buildings implies the migration from "compliance" to "performance" and the acceptance of a much more complex series of safety objectives. Life safety needs to be accompanied by property protection and the implicit safety associated to code compliance has to be substituted by a detailed assessment of performance using state of the art engineering tools. This section will provide a simple example to illustrate a methodological approach. This example is not intended to be exhaustive nor to solve the fire safety strategy in its integrity. Instead, it takes some aspects of the comprehensive analysis to highlight the value of a performance-based approach.

\subsection{Brief Description of the Building}

The Bastions Building at the University of Geneva was constructed between 1869-1871undergoing two series of renovations a first renovation of the Aula Magna in the period 1940-1944 and a retrofit of the roof in the period 1961-1963. The renovation of the Aula Magna changed its layout and introduced a series of vitreaux considered to be unique glass work from Geneva. The building has a central building and two wings covering a total surface area of $25,000 \mathrm{~m}^{2}$. Figure 4 shows an image of the building and Figure 5 images of some of the vitreaux. The building is not only a remarkable example of classic architecture of the late $19^{\text {th }}$ century but also houses murals, stone work and woodwork of exceptional value. Rehabilitation of the building will require adaptation to modern codes that not only implied significant reconfiguration of space but also the potential elimination of the vitreaux to maintain compartmentalization of the means of egress. This example does not correspond to any existing analysis or official documentation associated to this renovation. It is an independent alternative approach that is only used for illustration. 


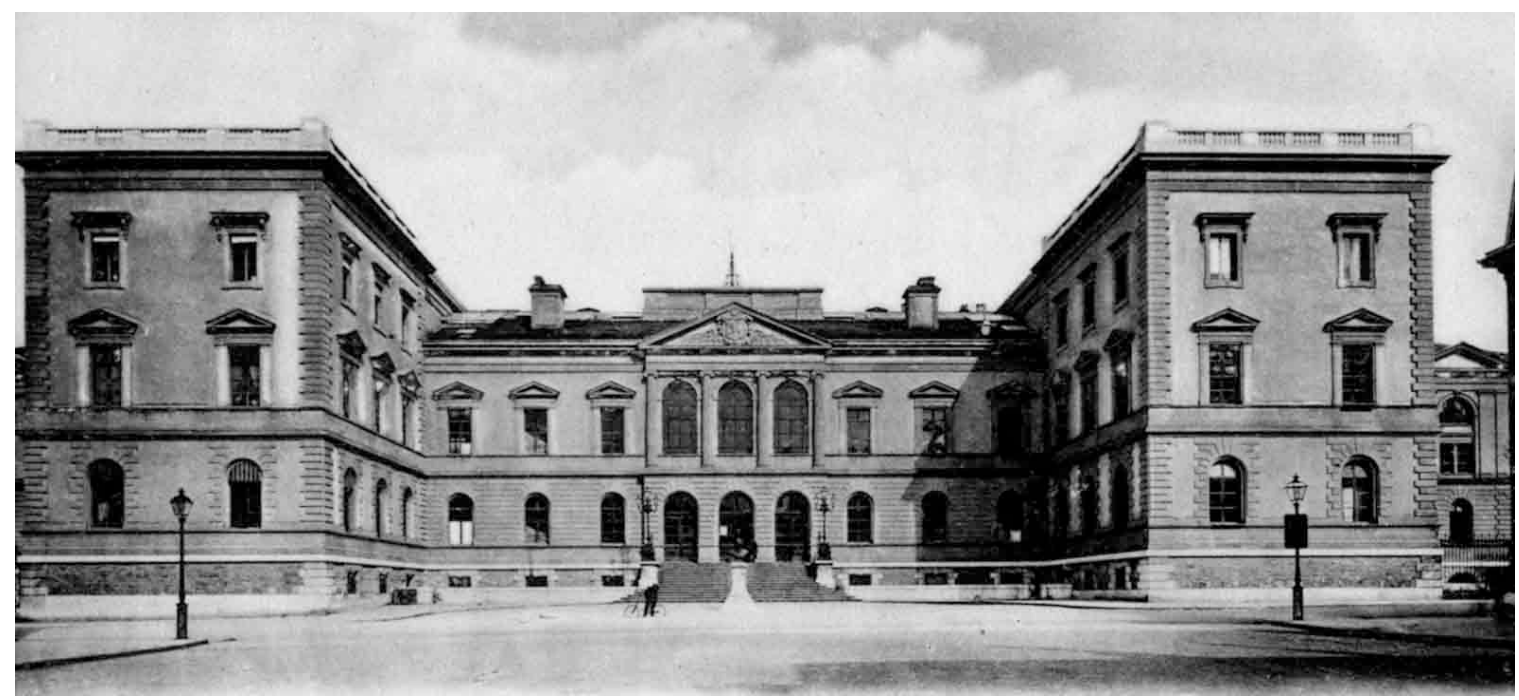

Figure 4. Photograph of the Bastions Building before the 1940 renovation work

\subsection{Proposed Compliant Solution}

Extracts from an existing code compliance analysis [32] are presented here to describe a series of modifications that will enable the building to comply with current building regulations. Figure 6 shows the existing building layout (ground floor). The main transit area is completely open and it includes the vitreaux with the second set of vitreaux forming part of the Aula Magna. The building in its current form has multiple deficiencies when it comes to addressing the egress of people. Addressing these deficiencies could potentially imply covering or eliminating the vitreaux to ensure fire resistance compliance. The corridors in all floors exceed maximum travel distances $-30 \mathrm{~m}$.

A solution implemented in a very similar building of the same complex compartmentalizes the corridors by means of an electrically activated mirror door that is intended to vanish by reflecting the corridor (as seen in Figure 6(b)). This type of solution has a questionable impact on the internal architecture of the building but also deteriorates circulation during normal operation of the building. As an emergency solution is not ideal because it relies on a mechanical device to close the door and compartmentalize the corridor in the event of a fire. Normally, solutions that require many moving parts are not deemed as robust and generally require high levels of maintenance. 

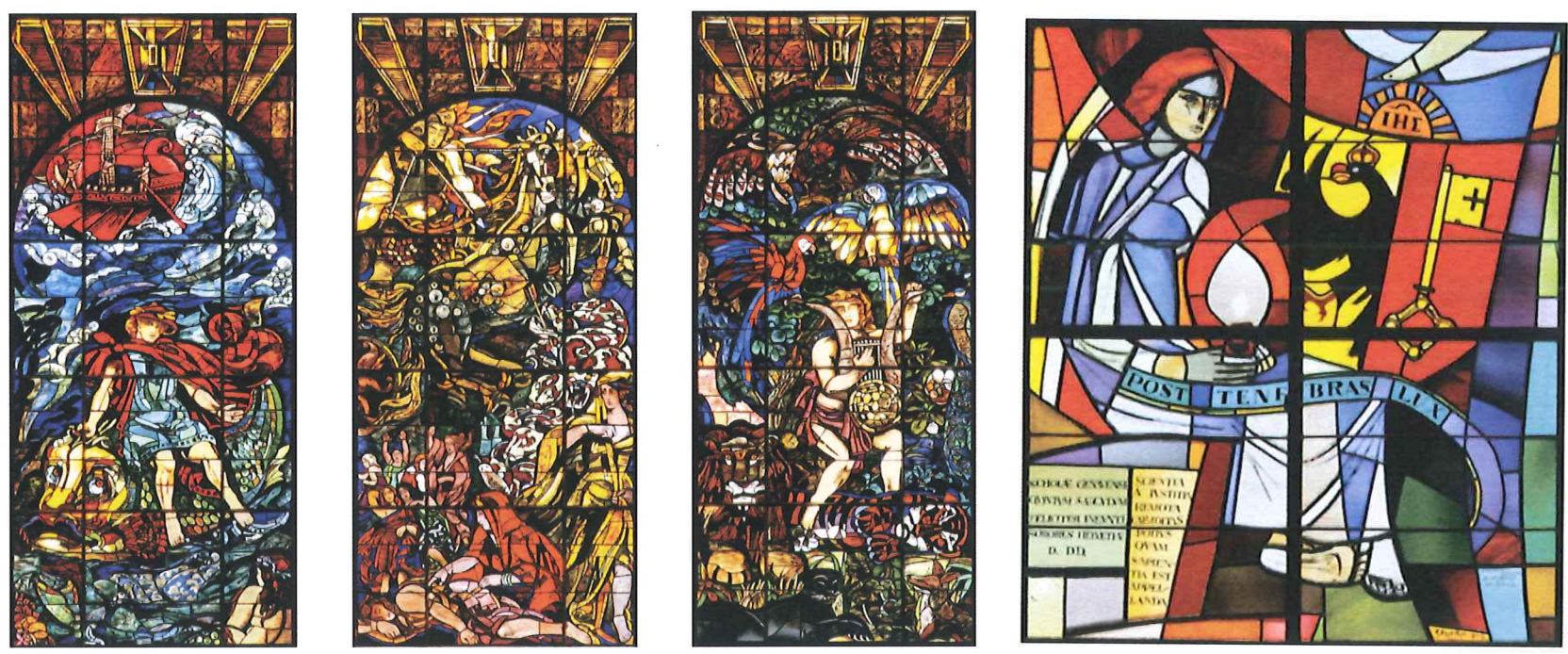

Figure 5. Vitreaux in the monumental stair and Aula Magna by Emilio Beretta (1958) and Alexandre Cingria (1940) [32]

The monumental stair (Figures 6(c) and 6(d) and Figure 7) cannot be fully enclosed therefore cannot serve as a means for emergency evacuation. As can be seen in Figure 6(d) there are attempts to partially enclose the stairs, but given the ceiling height and the architecture of the stair, these will all be very intrusive. Thus, alternative egress paths need to be constructed. Figure 6(a), 6(c) and 6(d) shows the proposed alternative and the location of two external stairs. In red are the modifications required. As it can be seen, the addition of external means of egress implies significant alteration to the façade which represents a potentially unacceptable intrusion on the architecture of the building. It is also important to note that internal stairs are generally a preferred solution for egress because smoke can be better managed and adequate egress conditions are easier to guarantee, particularly in areas where extreme weather conditions are possible [22]. Codes like NFPA [25] will normally suggest internal stairs.

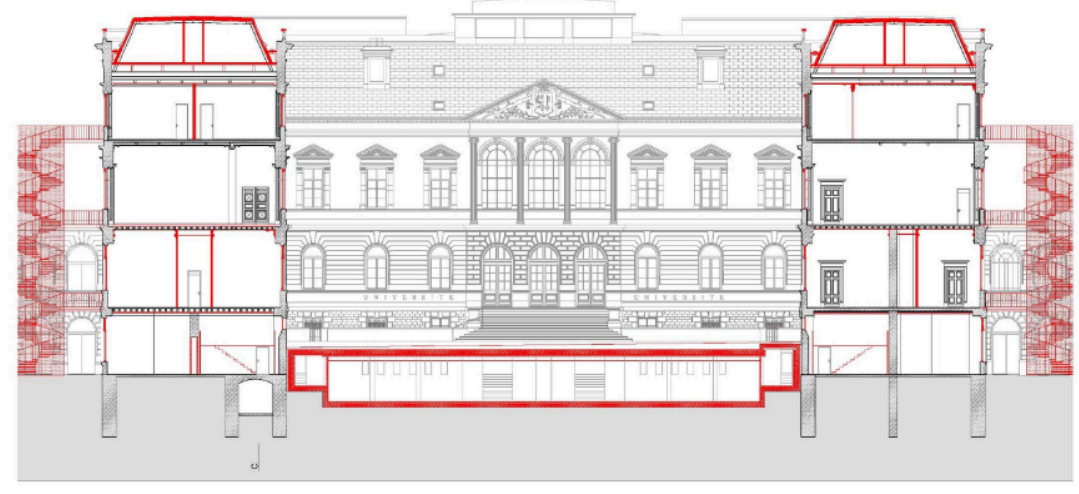

(a)

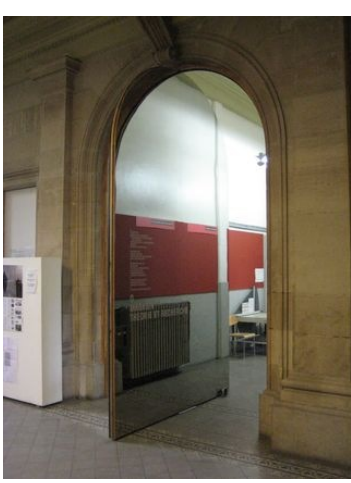

(b) 


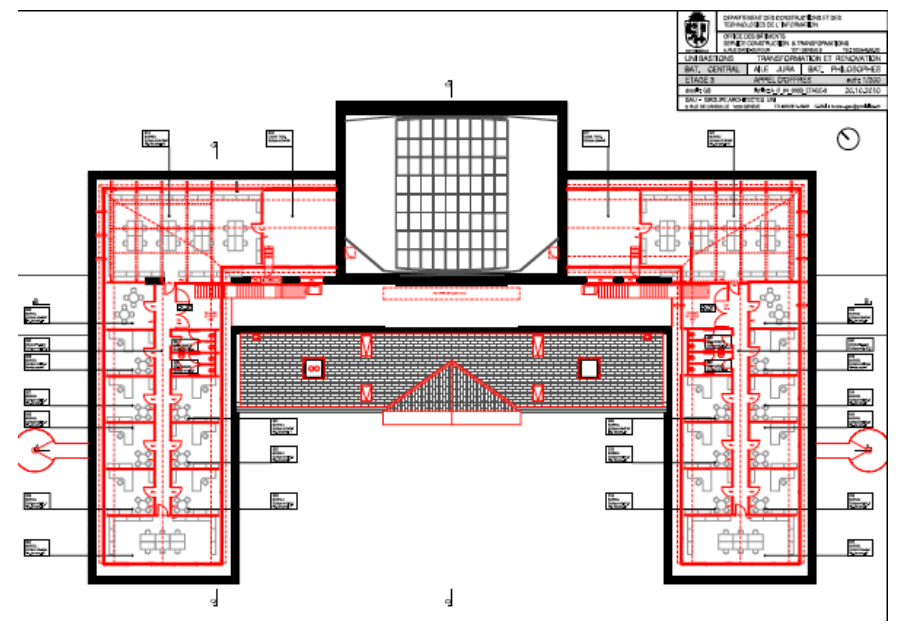

(c)

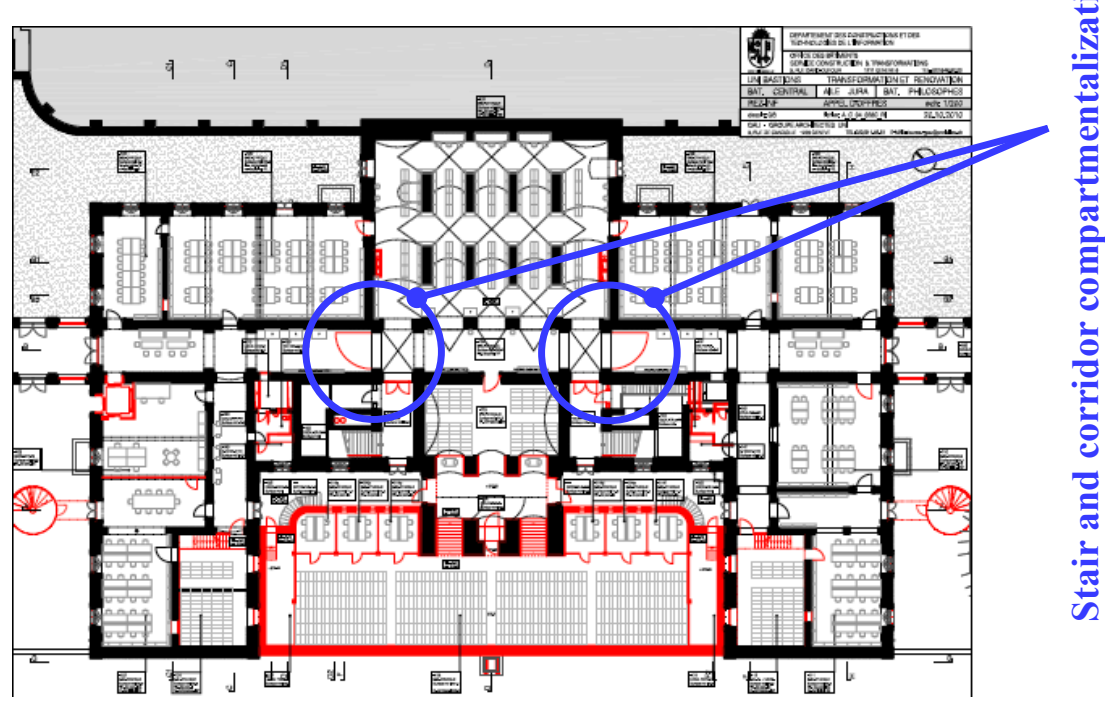

(d)

Figure 6. Proposed addition of new emergency egress paths and fire resistant structural elements [32] (a) front elevation (b) alternatives for compartmentalization used in similar building renovations in Geneva (mirror door) (c) Plan layout of the first floor showing in red fire resistant construction ad added emergency stairs (d) Plan layout of the ground floor showing in red fire resistant construction and the proposed compartmentalization of corridors and the monumental stair (blue circles).

\subsection{Alternative Approach to Smoke Management}

The alternative approach to introducing the mirror doors and the external escape stairs is to evaluate the potential fire growth (Equation (2)) use a zone model [21] to establish the time required for the smoke layer to descend to a point where it interacts with occupants. This is clearly a viable proposition because the floor to ceiling height is approximately $6 \mathrm{~m}$ and the corridors can be as wide as $7 \mathrm{~m}$, which gives a very significant volume. The larger the volume the slower the descent of the smoke layer and the easier to manage egress. The objective would be to achieve egress without any physical intervention on the building. The zone model was built specifically for this application based on the equations of reference [21]. 
A series of fires were analyzed and an example of the results is presented in Figure 8. The egress time has been calculated using simple empirical data for displacement velocities [22] and pre-movement times corresponding to educational facilities [22]. For the example illustrated in Figure 8 the egress time (RSET) is between 180-240 sec. These values were calculated using extremely conservative estimates. The methodology used is based on a free flow approach for the corridors and a density based approach for doors. It is important to note that the calculations presented in Figure 8 are only used for illustration purposes and are not intended as definitive quantifications. While sensitivity analyses were conducted with the fire and the parameters associated to egress, the presentation of these details goes beyond the scope of this paper.

The red and black curve correspond to the height of the smoke layer and the temperature of the smoke layer. The value of " $\alpha=0.00833$ " which corresponds to a slow growing fire. The corridors are almost free of combustibles; therefore, a slow growing fire is an acceptable growth rate. As can be seen from Figure 8, the smoke layer will descend $(\mathrm{z}(\mathrm{t}))$ to approximately to $3 \mathrm{~m}$ from the floor when everyone has already evacuated (most conservative). This means that people and smoke will not interact.

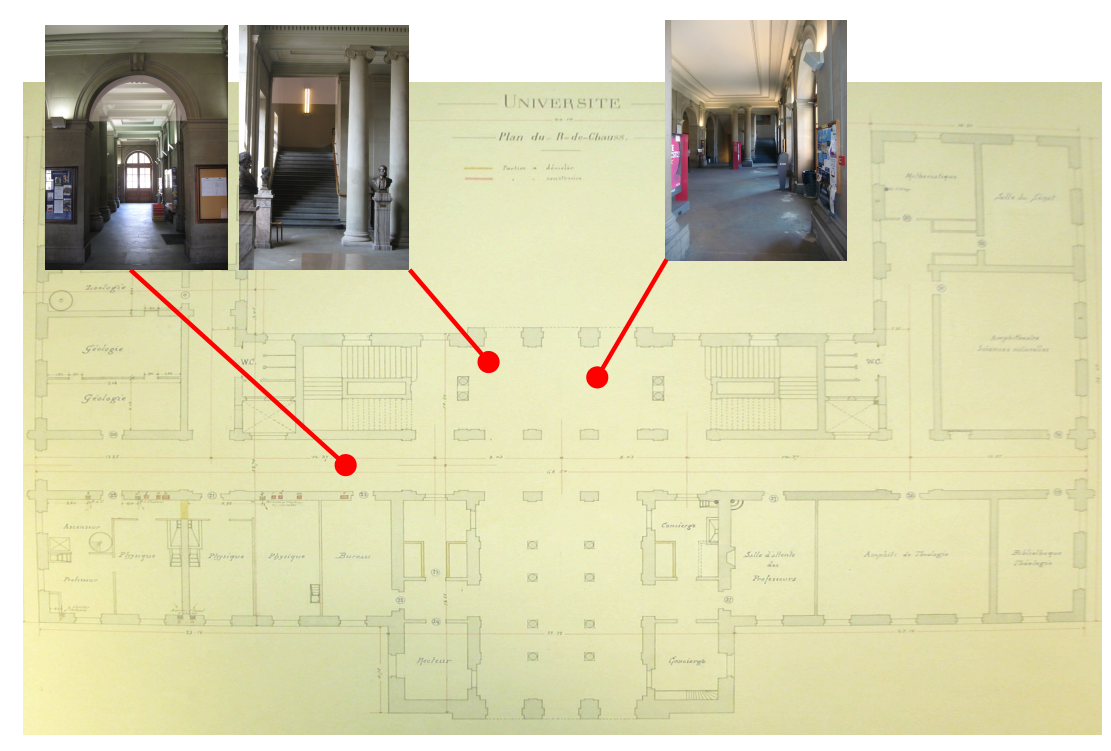

Figure 7. Existing building layout (ground floor). Inserted photographs of the egress paths.

Furthermore, the temperature of the smoke layer would have not reached $100^{\circ} \mathrm{C}$ by the time everyone has left the building. This is a smoke layer temperature that will still maintain safe conditions for occupants. This analysis demonstrates that the building design (i.e. geometry), while not compliant with building regulations, still provides a safe environment for occupants. It is important to note that this example is only presented to illustrate an alternative approach. In an analysis of this nature it is essential to demonstrate adequacy for numerous scenarios under different conditions. Furthermore, it is essential to take into account numerous variables including occupants with limited mobility, redundancies etc. Nevertheless, this example demonstrates that by taking advantage of the geometric characteristics of the building, it is possible to demonstrate that the building is safe while not being compliant. 


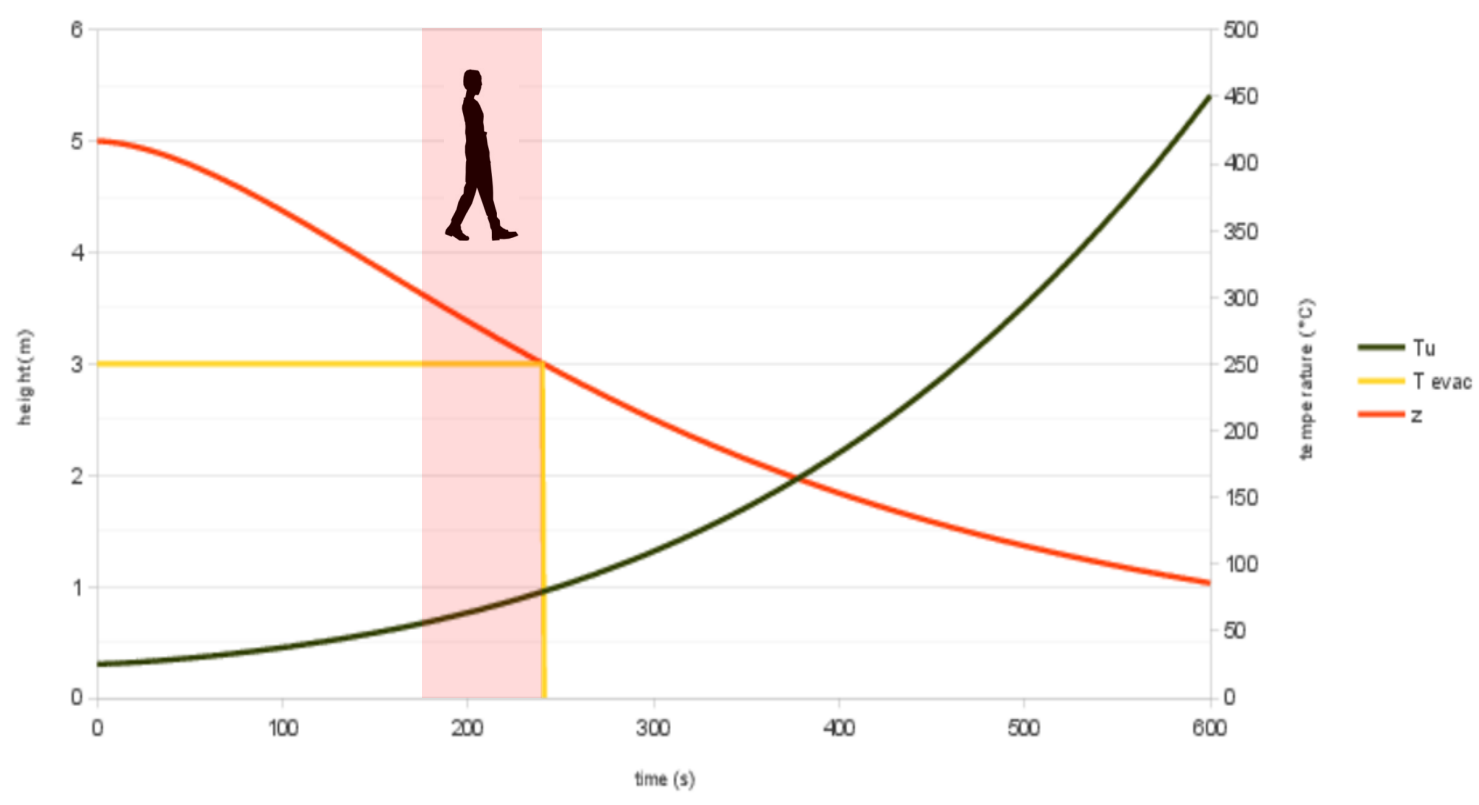

Figure 8. Performance evaluation of the egress paths.

In a similar manner, a fire dynamics analysis was conducted to demonstrate that flashover will not occur in any of the compartments. The ceiling height is sufficiently large that common furniture and contents of this building cannot generate sufficient heat to enable flashover to occur. This is of extreme importance because it shows that temperatures within the compartment will not reach values that will threaten the structure nor ignite timber. A compliant solution would require a fire resistance rating for all structural elements in red (Figure 6(a), 6(c) and 6(d)), this will have most likely implied encapsulation or replacement that might have include particularly valuable elements such as the vitreaux. The premise behind the fire resistance rating is the exposure of a structure to a post-flashover fire for a duration capable of consuming the integrity of the fuel content (i.e. time to burn-out) [10]. Given that the fire will not reach flashover, temperatures of the smoke layer can be estimated using a zone model and in this case indicate that they will never exceed $300^{\circ} \mathrm{C}$. This is consistent with values presented in the literature [29]. A detailed heat transfer and structural analysis could have been performed to demonstrate that the building structure offers adequate strength, nevertheless the estimated temperatures rendered this analysis unnecessary. Instead, only a heat transfer analysis was performed to establish any areas where a temperature increase, even mild, could create potential structural problems. This analysis identified no areas of concern. The focus then became compartmentalizing the smoke, which implies a detailed inspection of any possible smoke migration paths. Filling these paths to avoid smoke migration is most definitely a much less intrusive intervention.

For the doors, an extremely conservative assessment was made to establish that the doors were thick enough even if extreme charring rates were used to calculate fire damage. Despite the fire not reaching flashover, a localized fire can require the doors to withstand an intense fire for periods much longer than the egress times. So no modifications to the structure are required nor the replacement of the doors. Given that occupants can exit 
without any interaction with the smoke means that no intervention is necessary. The vitreaux can remain, the mirror doors are not necessary and the two proposed new means of escape can be omitted.

Identifying which compartments can attain flashover and establishing typical compartment temperatures allows to identify which sectors of the building are susceptible to significant damage. This is important because it allows to identify which areas of the building will put at risk valuable objects, thus will inform where valuable objects might have to be actively protected or displaced.

\section{Conclusions}

The solution to fire safety for historic buildings requires a performance assessment to explicitly demonstrate that the necessary fire safety objectives have been met. In the case of historic buildings, the fire safety objectives include life safety but also need to include adequate protection of the patrimony. Currently, the Fire Safety Engineering profession has adequate tools to conduct these analyses, allowing for unprecedented freedom in the manner in which adequate levels of safety are delivered. To be able to implement these tools it is necessary to understand that safety is not only attained by compliance and furthermore that compliance does not mean safety. Many historic buildings have features that make them inherently safe despite not being compliant with current codes. This paper has used an existing renovation as an example to illustrate this. This paper does not intend to question or analyze the approach used for the Bastions Building at the University of Geneva, but to use alternative analyses to demonstrate the options available towards a renovation that will be most respectful of the historical building.

\section{Acknowledgments}

This work was conducted while on sabbatical at Ecole Polytechnique Fédéral de Lausanne funded by the Landolt \& Cia Chair in Innovation for a Sustainable Future. The support of Dr. Michael Woodrow (Foster \& Partners) in the analysis of the building is much appreciated. The collaboration of the conservation authorities of the Ville de Genève is also acknowledged. This analysis is not intended to question or to conduct a rigorous fire safety engineering analysis of the buildings discussed but to use them as an example to illustrate a methodological approach.

\section{References}

[1] Bernardini, G. Fire Safety of Historical Buildings. Traditional Versus Innovative "Behavioural Design" Solutions by Using Wayfinding Systems; $1^{\text {st }}$ Edition, Springer International Publishing, 2017. 
[2] Carattin, E. and Brannigan, V., Controlled evacuation in historical and cultural structures : requirements, limitations and the potential for evacuation models, Proceedings of the $5^{\text {th }}$ International Symposium on Human Behavior in Fire, Interscience Communications Ltd., London, UK, pp. 447-459, 2012.

[3] Ornelas, C.; Guedes, J.M.; Breda-Vázquez, I. Cultural built heritage and intervention criteria: A systematic analysis of building codes and legislation of Southern European countries. Journal of Cultural Heritage 2016, 20, 725-732.

[4] Almeida, J.E., Rossetti, R.J.F., Coelho, A.L., The importance of prevention and emergency planning in Cultural Buildings, Cultural Heritage and Loss Prevention, 47-54, 2014.

[5] Marrion, C.E., More effectively addressing fire/disaster challenges to protect our cultural heritage, Journal of Cultural Heritage, 20, 746-749, 2016.

[6] NFPA 914, Code for Fire Protection of Historic Structures, Quincy, MA, National Fire Protection Association, 2001.

[7] British Standards Institute, The application on fire safety engineering principles to the design of buildings-Part 6: human factors: life safety strategies-occupant evacuation, behaviour and condition (sub-system 6), PD79746:2004, 2004.

[8] Watts, J.M. and Solomon R.E., Fire Safety Code for Historic Structures, Fire Technology, 38, 301-310, 2002.

[9] Bukowski, R.W. and Nuzzolese, V., Performance-based Fire Protection of Historical Structures, Fire Technology, 45, 23-42, 2009.

[10] ASTM-E-119, Standard Test Methods for Fire Tests of Building Construction and Materials, ASTM, 2015.

[11] Naziris, I.A., Lagaros, N.D. and Papaioannou, K. Optimized fire protection of cultural heritage structures based on the analytic hierarchy process, Journal of Building Engineering, 8, 292-304, 2016.

[12] Ibrahim, M.N., Abdul-Hamid, K., Ibrahim, M.S., Mohd-Din, A. and Yunus, R.M.; Yahya, M.R. The Development of Fire Risk Assessment Method for Heritage Building, Procedia Engineering, 20, 317-324, 2011.

[13] Frosini, G.; Biagini, C.; Capone, P.; Donato, V.; Giusti, T. HBIM and Fire Prevention in Historical Building Heritage Management. In Proceedings of the ISARC 2016 - Proceedings of the $33^{\text {rd }}$ International Symposium on Automation and Robotics in Construction and Mining; Auburn, Alabama, USA, 2016.

[14] Ferreira, T.M., Vicente, R., Raimundo Mendes da Silva, J.A., Varum, H., Costa, A., Maio, R. Urban fire risk: Evaluation and emergency planning, Journal of Cultural Heritage, 20, 739-745, 2016.

[15] Ellingwood, B.R. and Wen, Y.K., Risk-benefit-based design decisions for low-probability/high consequence earthquake events in Mid-America, Progress in Structural Engineering and Materials, 7, 56-70, 2005.

[16] Center for Chemical Process Safety of the American Institue of Chemical Engineers, Guidelines for Developing Quantitative Safety Risk Criteria, New Jersey: John Wiley \& Sons, 2009.

[17] Australian Government, "Work Health and Safety Act," 2011. [Online]. Available: http://www.comlaw.gov.au/Details/C2011A00137.

[18] R. Robinson and G. Francis, "SFAIRP vs ALARP," in Conference on Railway Excellence, Adelaide, 2014.

[19] Bankoff, G., Lubken, U. and Sand, J., Flammable Cities, Urban Conflagration and the Making of the Modern World, The University of Wisconsin Press, Madison, Wisconsin, 2012.

[20] Knowles, S.G., The Disaster Experts, Mastering Risk in Modern America, University of Pennsylvania Press, Philadelphia, Pennsylvania, 2011. 
[21] Karlsson, B. and Quintiere, J.G., Enclosure Fire Dynamics, CRC Press, Boca Raton, Florida, 2000.

[22] Hurley, M.J. and Rosenbaum, E.R., Performance-Based Fire Safety Design, CRC Press, Boca Raton, Florida, 2015.

[23] ASCE/SEI 7: Minimum Design Loads and Associated Criteria for Buildings and Other Structures, American Society of Civil Engineers: Structural Engineering Institute, Reston, VA, 2016.

[24] Torero, J.L. and Lane, B. "The Changing Face of Structural Design for Fire," International Fire Buyers Guide, August, 2004.

[25] NFPA Codes and Standards, National Fire Protection Association, Quincy Massachusetts, 2018.

[26] Drysdale, D.D., An Introduction to Fire Dynamics, John Wiley \& Sons, West Sussexs, UK, 2011.

[27] Abecassis Empis, C., Reszka, P., Steinhaus, T., Cowlard, A., Biteau, H., Welch, S., Rein G., and Torero, J.L., "Characterization of Dalmarnock Fire Test One," Experimental Thermal and Fluid Science, 32, Issue 7, pp. 1334-1343, 2008.

[28] www.notrehistoire.ch, "Genève, Ancienne École de Chimie," June 29 ${ }^{\text {th }}, 2008$.

[29] SFPE Handbook of Fire Protection Engineering, $5^{\text {th }}$ Edition, Gottuk, Hall, Harada, Hurley, Kuligowski, Puchovsky, Torero, Watts (Editors), 2015.

[30] UL Fire Resistance Directory, Underwriters Laboratories, Northbrook, IL, 2015.

[31] Wang, Y., Burgess, I., Wald, F. and Gillie, M., Performance-Based Fire Engineering of Structures, CRC Press, Boca Raton, Florida, 2013.

[32] Secrétariat du Grand Conseil, Projet présenté par le Conseil d'Etat, Date de dépôt : 21 juin 2017, PL 12149, Projet de loi Le GRAND CONSEIL de la République et canton de Genève. (http://ge.ch/grandconseil/data/texte/PL12149.pdf) 